\title{
Sustaining Student Engagement and Equity in Computing Departments During the COVID-19 Pandemic
}

\author{
Heather Thiry ${ }^{\dagger}$ \\ Ethnography \& Evaluation Research \\ University of Colorado, Boulder \\ Boulder, CO, USA \\ heather.thiry@colorado.edu
}

\author{
Sarah T. Hug \\ Colorado Evaluation \& Research Consulting \\ Westminster, CO, USA \\ hug@colorado.edu
}

\begin{abstract}
In spring of 2020, almost all campuses across the United States abruptly closed and shifted to remote instruction due to the COVID-19 pandemic. Students and faculty rapidly adjusted how they engaged in learning in a time of great social and economic upheaval. In this paper, we use the lens of equity-oriented student engagement to examine how computing departments facilitated student participation in educationally engaging activities during the campus closures. The National Science Foundation-funded INCLUDES Alliance, the Computing Alliance of Hispanic-Serving Institutions (CAHSI), is a network of computing departments dedicated to increasing the representation of Hispanics in computing education and careers. We present results from a survey administered in spring 2020 to over 900 CAHSI students in 14 computing departments at Hispanic-Serving Institutions and interviews with 30 faculty, department chairs, and leaders. Though students reported increased financial and mental health struggles, they reflected on the myriad ways that faculty and peers supported their learning and sustained their engagement in coursework and co-curricular opportunities. In response to the pandemic, faculty and student leaders structured supports, such as peer-led team learning sessions and student clubs, to operate effectively in remote environments to promote student engagement.
\end{abstract}

\section{CCS CONCEPTS}

Social and professional topics $\rightarrow$ Professional topics; Computing education; Adult education.

\section{KEYWORDS}

Hispanics, computing, student engagement, equity

\section{ACM Reference format:}

Heather Thiry \& Sarah T. Hug 2021. Sustaining Student Engagement and Equity in Computing Departments during the COVID-19 Pandemic. In Proceedings of the 52nd ACM Technical Symposium on Computer Science

Permission to make digital or hard copies of part or all of this work for personal or classroom use is granted without fee provided that copies are not made or distributed for profit or commercial advantage and that copies bear this notice and the full citation on the first page. Copyrights for third-party components of this work must be honored. For all other uses, contact the Owner/Author(s).

SIGCSE'21, March 13-20, 2021,Virtual Event, USA.

(C) 2021 Copyright is held by the owner/author(s)

ACM ISBN 978-1-4503-8062-1/21/03. https://doi.org/10.1145/3408877.3432381
Education (SIGCSE'21), March 13-20, 2021, Virtual Event, USA. ACM, NY, NY, USA, 7 pages. https://doi.org/10.1145/3408877.3432381

\section{Introduction}

In spring of 2020, higher education across the United States abruptly shifted to online instruction as campuses closed and states issued stay-at-home orders due to the COVID-19 pandemic. Recent reports and media stories paint a troubling picture of the impact of the pandemic on students and institutions during the spring semester. Students faced significant life disruptions, personal and academic challenges, and lacked a sense of belonging to their institutions [1]. Many students-especially those from historically underrepresented populations-lost jobs, research, and internship opportunities, and experienced other impediments to their academic progress [2].

Given the negative effects on underserved populations, we surmised that students at Hispanic-Serving Institutions (HSIs) may have experienced hardships and disruptions during the campus closures in spring 2020. To test this hypothesis, we collected data from computing students at HSIs to learn about their experiences during the pandemic. The Computing Alliance of Hispanic-Serving Institutions (CAHSI) is a long-standing network of computing departments that partners with industry, non-profits and other stakeholders to increase the representation of Hispanics in computing education and the workforce. Despite some recent progress, Hispanic/Latinx students are still underrepresented in computing at all educational stages. Though Hispanics account for $25 \%$ of the United States youth population [3], they only earn about $10 \%$ of undergraduate computing degrees [4]. However, about more than a third of Hispanic students receive their computing degrees from HSIs [4]. Therefore, HSIs are an important leverage point for increasing Hispanic/Latinx representation in computing.

To address this continued disparity, CAHSI developed a number of signature practices that have positively affected students' professional preparation and retention in computing [5, $6,7,8,9]$. In spring of 2020, the CAHSI network mobilized to provide resources and information to students during the rapid shift to remote learning. This paper will report survey and interview results that highlight the ways that institutions, departments, and faculty, in particular, worked to sustain student connection and engagement during this challenging time. 


\section{Engagement, Equity and Inclusion}

Student engagement in higher education, inside and outside of the classroom, has long been touted as the key to student success and retention $[10,11,12,13,14,15,16]$. Though research in this area has often focused on primarily white institutions and affluent student populations, recent studies have demonstrated the importance of robust student engagement for positive racial and gender identity development and for the success of students from underrepresented populations [17, 18, 19]. Therefore, maintaining robust student engagement during the COVID-19 may be particularly important for underrepresented populations of students in computing, such as Hispanics.

Student engagement is defined as participation in educationally effective practices, both inside and outside of the classroom [19]. Student engagement is often associated with "high-impact practices," which are a range of curricular and cocurricular practices (e.g., research experiences, internships, learning communities, collaborative projects, etc.) that have been shown to enhance student learning and promote persistence and retention [20, 13, 21]. High-impact practices are also related to the campus environment itself and student-faculty interactions [22. 23]. Student engagement is essential to academic success and retention because engagement strengthens students' academic and social integration to the institution, and, therefore, their commitment to complete their studies [15].

While engagement is critical to students' success and persistence, prior researchers have typically assumed that all students have equal access to opportunities and have not explored how engagement has been structured to privilege certain populations of students [19]. Recently, researchers have advocated an equity-oriented approach to engagement in which institutions intentionally design opportunities for engagement with the inclusion of underserved student communities in mind [19, 24, 25]. Equity-oriented engagement places the onus of student engagement on institutions to be inclusive and to ensure access to opportunities for all students $[18,19]$. Such an approach requires deep understanding of students' lives, listening to their concerns, and ample strategic planning to address systemic inequities [19]. The concept of equity-oriented engagement is helpful in understanding the experiences of students at Hispanic-serving institutions during the shift to remote learning in spring 2020 and for understanding how institutions, departments, and faculty structured learning and interactions to maintain student engagement during a turbulent time.

\section{Research Methodology}

\subsection{Research Design and Question}

This is a mixed-methods study of students' experiences during the COVID-19 pandemic in computing at Hispanic-serving institutions (HSIs). HSIs are notably diverse, enrolling at least 25\% Hispanic/Latinx students, and many HSIs encompass other forms of diversity, serving large numbers of low-income, firstgeneration college students, and other underrepresented minority groups. Therefore, our research question is:
How did computing students in HSIs experience the campus closures in spring 2020 and which institutional and departmental supports best facilitated their continued engagement in enriching curricular and co-curricular activities?

\subsection{Data Collection and Analysis}

The survey was developed in response to the COVID-19 pandemic and the rapid transition to remote learning. The survey was designed to understand the experiences of diverse students with all facets of the pandemic-academic, financial, social, emotional, and professional. Survey constructs measured the impact of the pandemic on students' interest, self-efficacy, aspirations, and access to opportunities for professional engagement (e.g., research, internships, etc.). The survey also measured students' engagement with faculty, peers, and other campus resources during the pandemic and institutional resources accessed. Finally, the survey measured the impact of the pandemic on students' financial, personal, and mental well-being. The survey was approved by the campus institutional review board.

The survey was distributed to all undergraduate students at 14 computing departments in Hispanic-Serving Institutions. In all, 918 students completed the survey in late spring of 2020. Students were sent a link to the electronic survey. Response rates varied by department and were typically in the range of 5\%-25\%.

Sixteen interviews were also conducted with 30 CAHSI leaders in April 2020, including department chairs, faculty, and CAHSI staff housed within participating departments. Some interviews were conducted individually, but representatives within individual departments were often interviewed as groups, typically comprising two or three participants. Interviews were semi-structured to allow for systematic collection of data, with flexibility to expand on certain topics or explore emerging themes [26]. Interview topics included leadership, student engagement, strategic planning, and pandemic responses.

Quantitative survey data were imported into SPSS statistical software and cleaned and organized. Clusters of items were grouped into scales and scale averages were computed. Internal reliability of scales was high (ranging from 0.80 to 0.95 on Cronbach's Alpha). Descriptive and inferential statistics were computed to understand patterns in the data and to discern differences among groups, such as race/ethnicity, gender, or other variables. Descriptive statistics included means and frequencies of all numeric and likert-scale items. As warranted, inferential statistics such as chi-square or Analysis of Variance (ANOVA) were conducted. Interview transcript data and open-ended survey items were coded using a grounded theory approach [27]. Data were inductively (e.g., based on emerging or unanticipated themes) and deductively (e.g., identifying examples of student engagement during the pandemic) sorted into codes through open coding and then organized into broader categories through axial coding. Five hundred sixty survey respondents provided open ended data across at least one of the seven open-ended survey items. Some of the codes utilized for open-ended survey items were "peer support," "faculty availability," and "technical support." Some of the axial codes (to identify broader domains of 
interest) used for the interview analysis were "student engagement," "COVID-19 responses," and "academic supports."

\subsection{Demographics of Survey Respondents}

A total of 918 students responded to the COVID-19 survey, with a modal item response of 738 . Respondents were all attendees at HSIs, and $48 \%$ identified as Hispanic (13\% Hispanic female, 35\% Hispanic male). Respondents were racially diverse: Ten percent were Asian female students, $18 \%$ Asian male students, 5\% Caucasian female, $17 \%$ Caucasian male, 2\% African American female, 4\% African American male, and 15 students self-identified as American Indian/Native American/ Pacific Islander/Native Hawaiian (note that some respondents marked multiple races/ethnicity). Most often, survey respondents were 4th year undergraduate students (41\%) or 3rd year students (30\%), though second year (15\%) and first year students (9\%) also participated. Six percent of respondents were graduate students (51 students). Students also came from a range of educational backgrounds; about $50 \%$ were first-generation college students and $41 \%$ were transfer students who began their undergraduate studies at a community college. Many students were also low-income as more than $50 \%$ reported that they received a Pell grant (a marker of low-income status as Pell grants are distributed to economic need).

\section{Research Findings}

First, we will describe students' experiences of the COVID-19 pandemic during spring 2020 to understand the context of computing students at Hispanic-Serving Institutions, many of whom are financially vulnerable and from underrepresented populations in computing. Next, we describe institutional and departmental actions and practices that supported students' continued engagement and professional development during remote learning.

\subsection{Understanding Student Contexts}

Overall, during the campus closures and stay-at-home orders in spring 2020, students expressed great anxiety, frustration, and difficulty in focusing academically, which was for many exacerbated by their home situations, available resources, and their health and financial circumstances. In all, $91 \%$ of students experienced emotional and personal challenges and 52\% of students were severely impacted (reported 3 or more mental health challenges related to the COVID-19 pandemic). Students reported an average of 2.62 negative mental health impacts each. The pandemic overwhelmingly influenced students' mental health and well-being; nearly $3 / 4$ of students reported greater stress; about $2 / 3$ reported greater anxiety, and nearly $40 \%$ experienced increased depression. Women were disproportionately impacted as they were significantly more likely to experience multiple mental health challenges $(\mathrm{X}=36.238, \mathrm{df}=12, \mathrm{p}=.000)$.

Many students faced increased financial hardship during the stay-at-home orders. Some students continued to work in paid positions, while others were laid off or furloughed from their jobs. Nearly $20 \%$ of students continued to work in their essential jobs.
However, some students lost income through layoffs, furloughs, or reduced hours. About one in eight students reported they had been laid off or furloughed, while another $15 \%$ had lost income or reduced hours at their work. Nearly $1 / 3$ of students had difficulty paying for food and other living expenses, and more than half of students experienced increased financial worry and stress. Therefore, students' financial, mental health, and personal struggles had enormous potential to negatively impact their academic performance, progress, and engagement in computing.

\subsection{Providing Access to Technology}

As courses moved online, students faced technical challenges. More than a third of students had unreliable wi-fi, while nearly $10 \%$ had no wi-fi at all in their home. Therefore, nearly half of students experienced internet issues that made remote learning difficult. Additionally, nearly $20 \%$ of students had old computers which impeded their capacity to fully participate in remote learning.

In an open-ended question, students described the technological challenges they faced. In some cases, students shared devices with many family members who were also working and learning from home. Other students did not have the technology they needed to participate, or bandwidth was insufficient for the household, as multiple users put a strain on the services. Students described some of the challenges:

"I did not have good access to internet. I had to cancel my internet plan due to financial crisis. Most of my classes are online but it's unclear what we are supposed to do.”

"Taking exams and quizzes at home can be difficult with a distracting family and an unstable wi-fi connection. I always feel stressed about not being able to finish on time when the wi-fi dies on me."

Students in rural areas described how even when they had access to internet services, the connection speeds were insufficient for Zoom meetings, or for using their cameras during Zoom sessions.

"It has also been the poor internet connection I have at home. It's been difficult to keep a good connection during live lectures."

"I don't have good internet. I lag a lot in class, and I can barely understand what they are talking about in class."

However, some departments and individual faculty members were proactive in ensuring students got the equipment they needed, as demonstrated in the following typical comment.

"My advisor and our lab was really helpful, they ensured that I had the equipment I needed to work from home on my projects."

In response to these technological needs, CAHSI universities provided technical support so students could continue their courses remotely. About $5 \%$ of students received laptop loans or 
wi-fi hotspots from their universities. This support was very significant for some students; in response to an open-ended question, some students reported that the greatest help they received was funding for internet services, hot spots, and laptop computers, or specific access to physical spaces to use internet. Some universities also kept a few buildings open so students could access wi-fi or computer labs.

"The free hotspot and internet help were a big help for me, since I would usually use the school's wifi to do homework or other places that were closed during the time."

"I received university funding to purchase a better laptop which greatly helped me as my other laptop was so slow it would take me a considerable amount of more time to do assignments or log into classes because it would freeze a lot.”

Faculty also played an important role in ensuring that students had the knowledge, tools, and confidence needed to engage in online learning since many students had not previously participated in online coursework. Students also described ways in which they experienced equity-oriented engagement through scaffolded uses of technology. Faculty who were proactive about the switch to remote learning set students up for success.

"My professor was helpful. Before the transition, he prepared us by having us join a test zoom meeting in case we were to have online classes. His foresight made the transition really smooth, to quickly resume classes."

"My AI teacher began preparing us for this weeks in advance. It was a smoother transition than other classes."

\subsection{Facilitating Interactions}

Given the many challenges faced by students during campus closures, faculty were students' most important source of support during remote learning in spring 2020. Most students reported that they had sought help from faculty during online instruction. More importantly, $84 \%$ of students found faculty help, in or out of the classroom, to be effective, with $41 \%$ of students finding it "very effective." However, students found the help received in class sessions to be more beneficial than the help they received outside of class from faculty ( $85 \%$ vs $60 \%$ ). Perceptions of support from faculty did not differ by student population, such as gender or race/ethnicity, suggesting that all students were equitably engaged with faculty in class sessions during remote instruction in the spring, although more so in class than outside of class sessions.

As isolation became the norm during lockdowns across the country, interactions were more important than ever, according to students. Faculty led this interactivity, especially by remaining accessible to students, being flexible, and providing personal encouragement and support during the challenging time.

"An instructor has taken 5 minutes before each class to ask about how are we handling the quarantine, if we are safe and if we have any problems, we can let him know, or our department. The University also provided psychological support."

"Two of my professors are very active with online communication and have adjusted their courses to reflect the different situation."

Students also assisted each other informally, as nearly three quarters of students reported that their interactions with peers and study groups outside of class helped their learning during the spring campus closures. Similar to other areas of support, access to and use of peer groups did not differ by student population, such as gender or race, indicating that all students equitably benefited from peer study support and peer-led sessions during remote learning. On the other hand, students did not perceive group assignments to be effective in remote learning environments, as only $57 \%$ of students rated formal, collaborative coursework as effective. In these cases, group work that was directed and organized by faculty before the COVID-19 pandemic hit was not always sustainable in remote learning environments. Student concerns with formal group work often emanated from the other disruptions that they faced.

"[The greatest challenge is] Having to work with peers on team projects because you can't get a hold of them."

"Dealing with my grandfather's death while being part of several group projects in which others are counting on me to do my part [was the greatest challenge]"

While faculty-directed peer interaction had mixed results, students who sought out informal support from peers were highly satisfied with these interactions and found them very helpful for succeeding in coursework.

"My classmates helped a lot. We just study before the exams."

"My classmates and friends are what helped make the transition to online classes bearable. After a difficult class, we would get in a group chat or schedule a video call and help one another understand the material."

In conclusion, faculty provided meaningful academic and personal support for students during remote learning. However, informal peer interaction was more helpful to students' learning than faculty-directed group assignments. Additionally, faculty support inside of class was more helpful than virtual office hours.

\subsection{Restructuring Academic Support Systems}

Students also turned to near-peers and peer leaders for cocurricular support, demonstrating the importance of the strong peer networks encouraged within CAHSI departments. Peer-led team learning (PLTL), in which near-peers guide students through supplemental exercises to enhance their conceptual understanding in introductory courses, is one of CAHSI's signature practices. At the onset of campus closures, CAHSI mobilized to transition PLTL 
to remote environments. Overall, $83 \%$ of students found the support they received from peer leaders to be effective during campus closures.

In one department, faculty, staff and students had just begun a long-term investment in PLTL sessions in introductory computing courses in the spring of 2020. In this instance, teaching assistants collaborated with peer leaders to design activities with guidance from the professor and a CAHSI staff member. The teaching assistants and the peer leaders attended all PLTL sessions, which were incorporated into lab time. Undergraduate peer leaders directed the activities while TAs supported students and answered questions as needed. As academic activities moved online, peer leaders and teaching assistants wanted to sustain the support to students at a distance, and developed synchronous Zoom sessions for all students to join at the same day and time as the labs that were held on campus. Some adjustments were made to ensure success-for instance, the sessions were co-hosted by more than one peer leader to accommodate unreliable wi-fi. These adaptations helped to sustain the engagement of all students in the co-curricular PLTL sessions. In an interview, a CAHSI staff member described the changes to PLTL to bring it online which had resulted in improved attendance at the sessions, in part because it was easier for students to fit the sessions into their busy schedules when they were held virtually.

"So, I think it's been going pretty well so far. I feel like we've lost a little bit, of the individual connection with a student and a peer leader... We have had probably at least $90 \%$ of the class come for the PLTL activity. And it seems like now that they're in their third week they are getting a little bit more interactive. "

Students who attended the PLTL sessions learned more than just programming skills-the peer leaders actively provided information about how to use departmental resources from afar, so students could continue to access the tools they need to be successful in computer science. In an interview, a departmental leader described how the peer leaders informed students about departmental resources.

"The peer leaders are sharing a bit more "insider tips," because most of these students are freshmen or sophomores, but insider tips about how to work within the CS system. One of the first things that we did when the students came back online is making sure that all the students connect to our local servers, connect to the lab computer, so if they didn't have certain programs on their computers they can go use them on a different computer. Most of them had never done that. I think the PLTL students are definitely learning things that will help them, in not just their content knowledge, but how they relate to the CS department itself."

The unconventional teaming of graduate teaching assistants and peer leaders created additional mentoring opportunities for the peer leaders, who were undergraduates in computer science. In an interview, a peer leader described the way she and her co- leaders asked for assistance with problems from the graduate student T.A.s.

"I also think there are just some problems that even when I would ask (another peer leader), it would kind of be like, 'Wait, what's happening?' We were all confused, that's for sure, when we would ask a TA, because this was definitely even above me at the moment, so they definitely feel like another level of help to us."

Due in part to restructured academic support systems that provided opportunities for interaction, academic help, and synchronous learning, students maintained their interest in computing throughout the campus closures in spring 2020. Indeed, $85 \%$ of students marked that they had maintained or increased their interest in computing on the scale of items related to interest. Students' aspirations remained high, too, as $87 \%$ reported that they had the same or an increased commitment to stay in their major. About the same percentage marked that their intention to pursue a computing career had been sustained or increased during the pandemic-related campus closures.

Through innovation and adaptation, CAHSI departments maintained educationally vital activities such as PLTL sessions to strengthen students' conceptual learning and peer support during remote instruction. Peer leaders also provided insight into other aspects of computing, such as navigating departmental resources. Finally, pairing graduate T.As. with peer leaders provided an extra source of support and mentoring during the crisis.

\subsection{Sustaining Co-Curricular Connections}

Another way that departments facilitated equity-oriented engagement for students during remote learning was support for co-curricular student activities. CAHSI staff and faculty supported student leaders in reaching out to peers for club meetings and for planning online workshops to continue to provide professional development, such as tips for remote interviewing. For some, the COVID-19 crisis may have slowed progress in developing student community, but for others, the crisis created opportunities to improvise and include students who may not otherwise be able to attend activities. A CAHSI departmental leaders noted:

\begin{abstract}
"So the students have been running all these workshops. They're like, "Okay, time to get back in the saddle, we don't want to lose kids." And we're having a big meeting this evening ....and they're going to start doing a Zoom hangout or Google hangout. The meeting will start this evening with the officers and the leaders talking about their stories about online telecommuting, COVID, and open it up for the students to share, to really glean what's important to them and where they might need added support."
\end{abstract}

In sum, shifting student engagement activities online, rather than cancelling them, helped to foster community by providing a venue for students to reflect on the COVID crisis and to support one another. These venues also provided a venue for students to communicate their concerns and struggles to faculty. 


\subsection{Maintaining Student Momentum}

Students' access to academic and professional pathways as well as their abilities to persist in computing shifted over the COVID-19 health crisis. Students were asked about the impact of COVID-19 on their computing pathways and were asked to mark any of 16 potential negative impacts that they may have experienced. More than $70 \%$ of students experienced at least one negative impact to their computing pathway; on average, students marked 1.6 negative impacts each. Students were affected academically and professionally by disrupted and cancelled activities. As a result, fifteen percent of students have considered not continuing their studies, nine percent were unable to complete required courses for their major, and $4 \%$ planned not to continue their studies in the fall. Additionally, $8 \%$ had to withdraw from at least one class and $6 \%$ had one or more of their classes cancelled. Still more will not be able to graduate when planned (12\%). Students also lost professional opportunities, including jobs offers that were rescinded (8\%), as well as internship or research opportunities that were cancelled (16\%).

Some student groups were disproportionately impacted by the pandemic. Juniors and seniors were more negatively impacted than freshman and sophomores (the former group averaged 1.68 negative impacts, while the latter averaged 1.45). First-year students experienced the least impact to their computing pathway, averaging 1.27 negative impacts. Other student groups were also disproportionately affected. Low-income students and historically underrepresented students (American Indian, African American and Latinx) were also more negatively impacted than their counterparts. For instance, students receiving Pell grants had significantly more negative professional impacts than those who do not receive a Pell grant $(\mathrm{t}=2.664, \mathrm{df}=701, \mathrm{p}=.008)$.

Faculty became concerned about students who were experiencing the cancellation of undergraduate research and internship opportunities in March, too late to secure other technical apprenticeships for the summer months. CAHSI leadership developed a RAPID grant proposal through the National Science Foundation to fund the preparation and implementation of a virtual REU (Research Experiences for Undergraduates) for affected students. More than sixty students and over 20 faculty participated in the REU. Faculty received training in online mentorship and began meeting with their students synchronously to discuss the research efforts of the new teams. The proposal development, training for faculty and students, and related resources came from a cross-regional CAHSI partnership. The timing of the REU, postponed because of the timing of funding received, ran into the fall semester to encourage retention throughout the 2020-21 academic year. This was viewed as a benefit to encourage student retention within the department.

\section{Limitations}

The study has several limitations that affect its replicability and generalizability. For one, the study is a descriptive case study of a particular, unique moment of time. The COVID-19 survey was designed to capture students' reactions to and experiences of stayat-home orders and campus closures that occurred in spring 2020.
Given that the goal of this study is to understand a particular context that happened in a moment of time, there is no opportunity to replicate or generalize the study given that COVID19 conditions and university responses are perpetually shifting. Moreover, the study was intended to better understand the experiences of computing students at Hispanic-Serving Institutions during the spring 2020 stay-at-home orders; therefore, other institutional types were not included in the study. More research is needed to understand how the pandemic is unfolding and currently impacting different populations of students' academic trajectories at different types of higher education institutions.

\section{Discussion and Conclusion}

Equitable student engagement in educationally enriching activities is vital for broadening participation in computing,yet is challenging to maintain in remote environments. While faculty and institutions adapted to the pandemic in spring 2020 to ensure continuity of education for students, there were clearly challenges in shifting to remote learning. These findings illustrate the need for increased faculty professional development in the use of remote teaching methods, especially how to transfer collaborative work or active learning to virtual environments. Institutions may consider how to integrate into their incentive and reward structures the increased workload for faculty that resulted from shifting courses to remote platforms and providing online help and support to students. The findings also highlight the need for virtual academic, psychological and other support services during the pandemic. Still, faculty and students themselves demonstrated innovative approaches to sustaining student engagement during a difficult semester.

All of the examples from this research study highlight the creative and innovative departmental adaptations to COVID-19 campus closures that were equity-focused and student-centered. Successful adaptations had the goal of sustaining student engagement and maintaining their academic progress and persistence. Approaches that were solely faculty-driven, such as group assignments, were somewhat less successful than approaches that were co-constructed by faculty and student leaders. Successful departments and faculty involved students in planning for how to sustain student engagement in the midst of the pandemic. In conclusion, this study illustrates the importance of fast, flexible and responsive departmental adaptations to crises that prioritize student engagement and equity for underserved students. The findings also highlight the value of including student leaders in the planning process to promote full access to equityoriented engagement opportunities at critical times.

\section{ACKNOWLEDGMENTS}

We acknowledge the leadership of the CAHSI INCLUDES Alliance for their support of this work and assistance in providing access to students and departments. We also acknowledge the contribution of Timothy J. Weston to survey development. This material is based upon work supported by the National Science Foundation under Grant No. (1834620, 1551221, 1761185). Any opinions, findings, conclusions, or recommendations expressed in this 
material are those of the authors and do not necessarily reflect the views of the National Science Foundation.

\section{REFERENCES}

[1] Melissa Blankstein, Jennifer K. Frederick and Christine Wolff-Eisenberg, 2020 Student Experiences During the Pandemic Pivot. Ithaka S+R.

[2] Estaban M. Aucejo, Jacob F. French, Maria Paola, Ugalde Araya, and Basit Zafar, 2020. The Impact of COVID-19 on Student Experiences and Expectations. Working paper 27392. National Bureau of Economic Research. Cambridge, MA.

[3] Mark Hugo Lopez, Jens Manuel Krogstad and Antonio Flores, 2018. Key Facts About Young Latinos, One of the Nation's Fastest Growing Populations. Pew Research Center. https://www.pewresearch.org/fact-tank/2018/09/13/key-factsabout-young-latinos/

[4] National Center for Science and Engineering Statistics [NCSES], 2020. The State of U.S. Science and Engineering, 2020. National Science Board, National Science Foundation. Alexandria, VA

[5] Ann O. Gates, Sarah Hug, Heather Thiry, Mohsen Beheshti, Enrico Pontelli, Nayda Santiago and Malek Adjouadi, 2011. The Computing Alliance of Hispanic-Serving Institutions: Supporting Hispanics at Critical Transition Points. ACM Trans Comp Ed 11 3, 1-21.

[6] Heather Thiry, Sarah T. Hug, \& Timothy J. Weston. 2011, The Computing Alliance of Hispanic-Serving Institutions: Enhancing the Success of Hispanic Undergraduates in Computing Disciplines. 7 Enr Mgmt 5,1, 32-56.

[7] Villa, E.Q., Kephart, K.,Ann O Gates, Heather Thiry \& Sarah T. Hug 2013 Affinity Research Groups in Practice: Apprenticing Students in Research. FEng Ed. 102, 3, 444-466.

[8\} Sarah T. Hug, Heather Thiry \& Ann Q. Gates. 2015; Strategies for Sustaining Change in Computer Science and Engineering Education. Frontiers in Education conference proceedings.

[9] Heather Thiry \& Sarah T. Hug 2020, Taking Management into Our Own Hands How Computing Departments Promote Inclusivity and Empower Students. American Educational Research Association conference proceedings.

[10] Alexander W. Astin, 1993. What Matters in College? Four Critical Years Revisited. Jossey-Bass, San Francisco, CA.

[11] George D. Kuh, 1993. In Their Own Words: What Students Learn Outside the Classroom. Am Ed Res $f$ 30, 2 (June 1993), 277-304. DOI https://doi.org/10.3102/00028312030002277

[12] George D. Kuh, 1995. The Other Curriculum: Out-of-Class Experience Associated with Student Learning and Personal Development. J High Ed 66, 2 (June 1995), 123-155. DOI https://doi.org/10.1080/00221546.1995.11774770
[13] George D. Kuh, 2008. High-Impact Practices: What they are, Who has Access to them, and Why they Matter. American Association of Colleges \& Universities. Washington, D.C.

14] Alberto Cabrera, Amaury Nora, Patrick T Terenzini, Ernest Pascarella and Linda S. Hagedorn, 1999. Campus Racial Climate and the Adjustment of Students to College: A Comparison Between White and African-American Students. J High Ed 70, 2 (March 1999), 134-160.

[15] Vincent Tinto, 1993. Leaving College: Rethinking the Causes and Cures of Student Attrition ( $2^{\text {nd }}$ ed). University of Chicago Press, Chicago, IL.

[16] Vincent Tinto, 1999. Taking Retention Seriously: Rethinking the First Year of College. NACADA J 19, 2 (Fall 1999). 5-9.

[17] Shaun R. Harper and Anthony L. Antonio, 2008. Not by Accident: Intentionality in Diversity, Learning, and Engagement. In Shaun R. Harper (ed.) Creating Inclusive Campus Environments for Cross-Cultural Learning and Student Engagement. 1-18. NASPA, Washington, D.C.

[18] Lori D. Patton, Kristen A. Renn,, Florence M. Guido and Stephen John Quaye, 2016. Student Development in College: Theory, Research and Practice. John Wiley and Sons, Hoboken, NJ.

[19] Stephen John Ouaye, Shaun R. Harper and Sulman R. Pendakur (eds), 2019. Student Engagement in Higher Education: Theoretical Perspectives and Practical Approaches for Diverse Populations. Routledge, Milton Park, Abingdon.

[20] Marcia B. Baxter Magolda, 1992. Cocurricular Influences on College Students Intellectual Development. f Coll Stu Dev 33, 3, (Fall 1992), 203-213.

[21] Ernest T. Pascarella and Patrick T. Terenzini, 2005. How College Affects Students A Third Decade of Research, Vol 2. Jossey-Bass, Indianapolis, IN.

[22] Samuel D. Museus, 2014. The Culturally Engaging Campus Environments (CECE) Model: A New Theory of Success Among Racially Diverse Student Populations. Higher Education: Handbook of Theory and Research. Springer, Dordecht.

[23] Ernest T. Pascarella, Tricia A. Siefert and Charles Blaich, 2010. How Effective are the NSSE Benchmarks in Predicting Important Educational Outcomes?, Change Mag High Lrn 42, 1 (January 2010), 16-22.

[24] Shaun R. Harper, 2007. Using Oualitative Methods to Assess Student Trajectories and College Impact. New Directions for Institutional Research, 136,(Winter 2007), 55-68.

[25] Shaun R. Harper, 2011. Strategy and Intentionality in Practice. In J.H. Schuh, S.R Jones and S.R. Harper (eds). Student Services: A Handbook for the Profession. $5^{\text {th }}$ ed, 287-302. Jossey-Bass, San Francisco, CA.

[26] Andrea Fontana and James Frey, 1994. The Art of Science. In Yvonne Lincoln and Norman Denzin (eds). The Handbook of Qualitative Research, 361-376, Sage Publishing, Thousand Oaks, CA.

[27] Barney Glaser and Anselm Strauss, 1967. Discovery of Grounded Theory: Strategies for Qualitative Research. Aldine, Chicago. 